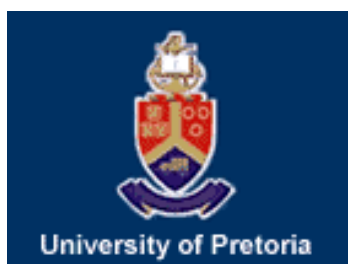

University of Pretoria

Department of Economics Working Paper Series

South African Stock Return Predictability in the Context of Data Mining: The Role of Financial Variables and International Stock Returns

Rangan Gupta

University of Pretoria

Mampho P. Modise

University of Pretoria

Working Paper: 2010-27

December 2010

Department of Economics

University of Pretoria

0002, Pretoria

South Africa

Tel: +27124204125 


\title{
South African Stock Return Predictability in the Context Data Mining: The Role of Financial Variables and International Stock Returns
}

\author{
Rangan Gupta* and Mampho P. Modise **
}

\begin{abstract}
In this paper, we examine the predictive ability, both in-sample and the out-of-sample, for South African stock returns using a number of financial variables, based on monthly data with an in-sample period covering 1990:01 to 1996:12 and the out-of-sample period of 1997:01 to 2010:04. We use the $t$-statistic corresponding to the slope coefficient in a predictive regression model for in-sample predictions, while for the out-of-sample, the MSE-F and the ENC-NEW tests statistics with good power properties were utilised. To guard against data mining, a bootstrap procedure was employed for calculating the critical values of both the in-sample and out-of-sample test statistics. Furthermore, we use a procedure that combines general-to-specific model selection with out-of-sample tests of predictive ability to analyse the predictive power of each financial variable. Our results show that, for the in-sample test statistic, only the stock returns for our major trading partners have predictive power at certain short and long run horizons. For the out-ofsample tests, the Treasury bill rate and the term spread together with the stock returns for our major trading partners show predictive power both at short and long run horizons. When accounting for data mining, the maximal out-of-sample test statistics become insignificant from 6-months onward suggesting that the evidence of the out-ofsample predictability at longer horizons is due to data mining. The general-to-specific model shows that valuation ratios contain very useful information that explains the behaviour of stock returns, despite their inability to predict stock return at any horizon.
\end{abstract}

Keywords: Stock return predictability; Financial variables; Nested models; In-sample tests; Out-of-sample tests; Data mining; General-to-specific model selection.

JEL Codes: C22, C52, C53, G12, G14.

\footnotetext{
* Corresponding author. Contact details: Professor, Department of Economics, University of Pretoria, Pretoria, 0002, South Africa. Phone:+ 2712420 3460,Email: Rangan.Gupta@up.ac.za.

** Graduate Student, Department of Economics, University of Pretoria. Contact details: Department of Economics, University of Pretoria, Pretoria, 0002, South Africa. Email: mamphomodise@yahoo.com.
} 


\section{Introduction}

The recent financial turmoil has once again highlighted the importance of accurate forecasting, especially when it involves predicting the path of leading indicators of the economy. There exists international evidence that asset prices, including stock prices, not only help in predicting output and inflation by acting as leading indicators (Stock and Watson, 2003), but also that there are major (asymmetric) spillovers from the stock markets to the real sector of the economy (for some recent evidence, refer to, Lettau and Ludvigson, 2001, 2004; Lettau et al. 2002; Apergis and Miller, 2004, 2005a, b, 2006; Rapach and Strauss, 2006, 2007; Pavlidis et al. 2009 and Das et al., forthcoming, amongst others). Hence, obtaining accurate predictions of stock prices cannot be understated, since if predicted accurately, the forecasts not only paves a path for relevant policy decision in advance, but can also provide important information for policy makers to appropriately design policies to avoid the impending crisis.

In a recent study, Gupta and Modise (2010), using monthly South African data for 1990:01-2009:10, examined the in-sample predictability of real stock prices based on valuation ratios, namely, price-dividend and price-earnings ratios. The authors could not detect either short-horizon or long-horizon predictability; that is, the hypothesis that the current value of a valuation ratio is uncorrelated with future stock price changes cannot be rejected at both short- and long- horizons based on bootstrapped critical values constructed from both linear and non-linear representations of the data. Gupta and Modise (2010), however, note that, future research should aim to investigate not only insample, but also out-of-sample predictability of real stock returns based on a wider set of financial variables, since it is possible for a variable to carry significant out-of-sample information even when it is not the case in-sample (Rapach et al., 2005; Rapach and Wohar, 2006). In addition, Gupta and Modise (2010), following the recent work by Rapach et al., (2010), suggested the need to analyze the role played by stock returns of major trading partners of South Africa in explaining the future path of the growth rate of real stock prices.

Against this backdrop, we aim to implement the above set of extensions suggested by Gupta and Modise (2010). To the best of our knowledge, this is the first study using south African data that looks at not only in-sample, but also out-of-sample forecasting ability stock returns of major trading partners of South Africa, besides, valuation ratios (Campbell and Shiller, 1998)), term spread (Campbell, 1987), short-term interest rate (Ang \& Bekaert, 2001), and payout ratio (Lamont, 1998). Following the extant literature, our stock price predictions are based on a predictive regression model, which essentially amounts to regressing the growth rate of real stock price (over various horizons) on a variable thought to be capable of explaining the future path of stock prices. Based on data availability, our in-sample period covers the period from 1990:01 to 1996:12, while our out-of-sample period begins from 1997:01 to 2010:04. Note, the choice of the outof-sample period is aimed to cover the effects of the East Asian crisis, the Argentinean currency crisis, the move to an inflation-targeting regime, and the recent financial turmoil. We assess in-sample predictability via the $t$-statistic corresponding to the slope coefficient in a predictive regression model. In order to test for out-of-sample predictability, we compare out-of-sample forecasts generated by a model of constant returns to forecasts generated by a model that utilizes a given financial variable using two recently developed powerful test statistics by Clark and McCracken (2001) and McCracken (2004). In addition, following the argument by Inoue and Kilian (2002) that both in-sample and out-of-sample tests are subject to potential data mining problems, we address issues of possible data mining by computing appropriate critical values for all the 
test statistics using data-mining-robust bootstrap procedure. Finally, following Clark (2004), we first use general-to-specific model selection approach in order to choose the best forecasting model based on in-sample data, where we start with a model that includes all the variables. The selected model, in turn, is used to compute forecasts over the out-of-sample period, again based on the Clark and McCracken (2001) and McCracken (2004) test statistics. As before, to guard against overfitting, we base our inferences on a data-mining-robust bootstrap procedure.

Our results show that most of the financial variables in the vast literature show no insample predictive power on South Africa's stock returns. Only the stock returns for our major trading partners have relatively strong predictive power on stock returns at longer horizons. For the out-of-sample period only two extra financial variables show some predictive ability. The Treasury bill rate shows predictive ability from 3-months-ahead horizon, while the term-spread has relatively weak predictive ability and it's only at a 1month-ahead horizon. Accounting for data mining, only the in-sample test remains significant at all horizons, while for the out-of-sample (from 6-month-ahead horizon) both the MSE-F and the ENC-NEW test statistics lack the predictive power. On the other hand, the model that combines general-to-specific model selection with out-ofsample test statistics shows interesting results. In all the horizons, at least one valuation ratio is included in the model specification. This may suggest that valuation ratios contain important information about stock return behaviour in South Africa, despite our earlier results showing no predictive ability in both in-sample and out-of-sample periods. The rest of the organised as follows: section 2 discusses the econometric models (in-sample and out-of-sample); sections 3 outlines the data and the results obtained from the models. The section further contains the specifications of the general-to-specific model and the results obtained; section 4 summarises our main findings and concludes.

\section{Econometric methodology}

\subsection{In-sample predictability}

Following extant literature, including Rapach and Wohar (2006) and Campbell and Shiller (1998), amongst others, we used a predictive regression model to analyse the behaviour of the stock return in long horizon. The predictive regression takes the form,

$y_{t+k}=\alpha+\beta x_{t}+\mu_{t+k}$

where $y_{t+k}$ is the log real return to holding stock from period $t$ to $t+k, x_{t}$ represents the fundamentals used in predicting future real stock returns and $\mu_{t+k}$ is the error term. When $\beta=0$ then the variable $x_{t}$ has no predictive power for future stock return (null hypothesis), while under the alternative hypothesis, $x_{t}$ does have predictive power for future returns $(\beta \neq 0)$ where all financial variables are specified such that $\beta>0$. The predictive ability of $x_{t}$ is typically assessed by examining the $t$-statistic corresponding

to $\hat{\beta}$, the OLS estimate of $\beta$ in equation (1), together with the goodness of fit measure, $R^{2}$.

Although equation (1) is widely used, it poses potential problems when estimating future stock returns. The first problem is small-sample bias, as $x_{t}$ is not exogenous regression 
in equation (1). Rapach \& Wohar (2006) show a case when $k=1$ to illustrate the biasness in $\beta$. Another potential problem emerges when $k>1$ in the predictive regression model, equation (1). The observations for the regression in equation (1) are overlapping when $k>1$ and thus induces serial correlation in the error term, $\mu_{t+k}$. To account for this, we use Newey and West (1987) standard errors, as these take into account serial correlation and heteroscedasticity in the error term, $\mu_{t+k}$. Further, we used the Bartlett Kerner and the truncation parameter of $[1.5 \bullet k]$, where $[\bullet]$ is the nearest integer function, when calculating Newey and West (1987) standard errors to compute $t$ statistic. There still exist the potential for serious size distortions when basing inferences on standard asymptotic distribution theory (Nelson \& Kim, 1993; Kirby, 1997 and Rapach and Wohar, 2005). Recent literature, including Rapach \& Wohar (2005), Killian (1999), Kothari \& Shanken (1997), amongst others, suggests using a bootstrap procedure to base inference concerning $\beta$ in equation (1) in an attempt to guard against potential size distortions. Rapach and Wohar (2005) lay out the full discussion of the bootstrap procedure that we use in our analysis. Basically we calculate the $t$-statistics corresponding to $\beta$ using the bootstrap procedure. We further repeat the process 1000 times to obtain an empirical distribution for the $t$-statistic. The p-value obtained is the proportion of the bootstrap statistics that are greater than the statistic computed using the original sample.

\subsection{Out-of-sample predictability}

Similar to Rapach \& Wohar (2006) and Rapach et al (2005), we further perform the outof-sample tests for stock return predictability based on the following recursive scheme. I is divided into in-sample and out-of-sample portions. The in-sample observations span the first $\mathrm{R}$ observations for $r_{t}$ and $x_{t}$ and the out-of-sample portion spans the last $P$ observation for $r_{t}$ and $x_{t}$. Firstly, the out-of-sample forecast for the "unrestricted" predictive regression model, equation (1), is generated as follows: we firstly estimated equation (1) via OLS using data available through period $\mathrm{R}\left(x_{1}, \ldots, x_{R-k}, y_{1+k}, \ldots, y_{(R-k)+k}\right)$ with the obtained OLS parameter, estimates from the predictive regression and $x_{t}$, we constructed a forecast for $y_{R+k}$ based on the unrestricted predictive regression model using $\hat{y}_{1, R+k}=\hat{\alpha}_{1, R}+\hat{\beta}_{1, R} \cdot x_{R}$ where $\hat{\alpha}_{1, R}$ and $\hat{\beta}_{1, R}$ are the OLS estimates of $\alpha$ and $\beta$ in equation (1) using data availability to R. The forecast errors are given by $\hat{\mu}_{1, R+k}=\hat{y}_{R+k}+\hat{y}_{1, R+k}$

The initial forecast for the restricted predictive model is generated in a similar manner except that $\beta=0$ in the predictive regression model, equation (1). We therefore, estimate the restricted model with $\beta=0$, via OLS using available data through period $\mathrm{R}$ to form the forecast $\hat{y}_{0, R+1}=\hat{\alpha}_{0, R}$

Where $\alpha_{0, R}$ is the OLS estimate of $\alpha$ in equation 1 and $\beta$ is restricted to zero using data available through period $R$.

$\hat{\mu}_{0, R+k}=\hat{y}_{R+k}+\hat{y}_{0, R+k}$ denotes the forecast error corresponding to the restricted model. The period is then updated by using data available through $R+1$ to generate a second set of forecasts. We estimate both the unrestricted and the restricted predictive regression models using data available through period $R+1$ and use these parameter 
estimates and the observations for $x_{R+1}$ in order to form unrestricted and restricted model forecasts for $y_{(R+1)+k}$ and their forecast errors, $\hat{\mu}_{1,(R+1)+k}$ and $\hat{\mu}_{0,(R+1)+k}$. We repeat this process for the entire available sample, resulting in two sets of $T-R-K+1$ recursive forecast errors. With $\left\{\hat{\mu}_{1, t+k}\right\}_{t=R}^{t=T-k}$ for the unrestricted predictive regression model and $\left\{\hat{\mu}_{0, t+k}\right\}_{t=R}^{T-k}$ for the restricted model.

We then compute the out-of-sample forecasts from the restricted and the unrestricted predictive models. The variable $z_{t}$ improves the out-of-sample forecast of $y_{t+1}$ relative to the first-order autocorrelation (AR) benchmark model which excludes $z_{t}$ if the unrestricted model forecasts are superior to the restricted model forecasts. Following Rapach and Wohar (2006), we use the Theil's U statistic, the ratio of the unrestricted model forecast root-mean-squared error (RMSE) to the restricted model forecast RMSE. If the RMSE for the unrestricted model forecast is less than the RMSE for the restricted model forecast, then $U<1$. To test for the superiority of the unrestricted model forecast to the restricted model forecast, we followed the MSE-F statistics in McCracken (2004) and also used by Rapach and Wohar (2005). We further use the variant used in Diebold and Mariano (1995) and West (1996) statistic designed to test for equal predictive ability. To test for forecast encompassing, we use the variant of the Harvey et al (1998), the ENC-NEW statistic.

To test the null hypothesis that the unrestricted model forecast MSE is equal to the MSE for the restricted model against the alternative that the unrestricted model forecast MSE is less than the MSE forecast for the restricted model, we use the MSE-F statistic. The MSE-F statistic is based on the loss differential,

$\hat{d}_{t+k}=\left(\hat{\mu}_{0, t+k}\right)^{2}-\left(\hat{\mu}_{1, t+k}\right)^{2}$

Let: $\bar{d}=(T-R-k+1)^{-1} \sum_{t=R}^{T-k} \hat{d}_{t+k}=M S E_{0}-M S E_{1}$

Where: $M S E_{i}=\sum_{t=R}^{T-k} \hat{d}_{t+k}\left(\hat{\mu}_{i, t+k}\right)^{2}, i=0,1$

The MSE-F statistic is then given by:

$M S E-F=(T-R-k+1) . d / M S E_{1}$

A significant MSE-F indicates that the unrestricted model forecasts are statistically superior to those of the restricted model.

On the other hand, the ENC-NEW is based on optimally constructed composite forecasts. If the forecasts from the restricted regression model encompass the unrestricted model forecasts, the financial variables provide no useful additional information for predicting stock returns relative to a model of constant expected returns. However, if the restricted model forecasts do not encompass the unrestricted model forecasts, then the financial variables provide useful information for predicting stock returns beyond the information already contained in the model that excludes the financial variables. The Clack and McCracken (2001) ENC-NEW is given by:

$E N C-N E W=(T-R-k+1) . c / M S E_{1}$

where: 


$$
\hat{c}_{t+k}=\hat{\mu}_{0, t+k}\left(\hat{\mu}_{0, t+k}-\hat{\mu}_{1, t+k}\right) \text { and } \bar{c}=(T-R-k+1)^{-1} \sum_{t=R}^{T-k} \hat{c}_{t+k}
$$

Using the MSE-F and the ENC-NEW have a number of advantages including accounting for parameter uncertainty inherent in estimating the unrestricted and the restricted model that are used to form the competing forecast. Further, the MSE-F and the ENC-NEW statistics have good size properties and are more powerful. The two test statistics, however, have limiting distribution which in non-standard and pivotal for $k=1$ and it is non-standard and non-pivotal for $k>1$ when comparing forecasts from nested models. As a result, we follow a bootstrap procedure in Rapach and Wohar (2006) as well as in Clark and McCracken (2001). As is the in-sample case, we use the bootstrap procedure to calculate the $t$-statistics corresponding to the MSE-F and the ENC-NEW statistics. This process is also repeated 1000 times to obtain an empirical distribution for the $t$-statistic. The p-value obtained is the proportion of the bootstrap statistics that are greater than the statistic computed using the original sample.

Rapach and Wohar (2005) point out that using a large number of financial variables to predict real stock returns poses data mining in both in-sample and out-of-sample tests of predictability. To control for data mining we use appropriate critical values for both our in-sample and out-of-sample predictability tests. We follow the data mining procedure in Rapach and Wohar (2005) for our analysis. We basically use the maximal MSE-F and the ENC-NEW for the out-of-sample test statistics and the maximal $t$-statistic for the insample test statistic. We derived the asymptotic distribution for the maximal in-sample and the out-of-sample statistics under no predictability and the alternative hypothesis in the data mining environment. Due to the limiting distribution which are generally datadependent (making inferences based on asymptotic distributions difficult), we use a bootstrap procedure in Rapach et al (2005) and Rapach and Wohar (2006). The bootstrap procedure that we follow is similar to the one in the previous section, but it is modified to explicitly account for data mining.

\section{Empirical results}

\subsection{Data analysis}

We use monthly data from 1990:01 to 1996:12 for the in-sample period and 1997:07 to 2010: 04 as the out-of-sample period for the stock returns and the other financial variables. The variables are discussed below:

Allshare index: Real stock returns for South Africa, computed as the first difference in the log-levels of real All Share Stock Index (ALSI);

Price-dividend ratio (log-level): the one-year moving sum of the ratio of nominal dividend to nominal stock prices;

Price-earnings ratio (log-level): the one-year moving sum of the ratio the ratio of nominal earnings to nominal stock prices;

Payout ratio (log-level): the ratio of price-earnings to the price dividend ratio;

Treasury bill rate: First difference of the 90 days Treasury bill rate. Using unit root tests, we found that the Treasury bill rate has a unit root. We, therefore, took the first difference to obtain a stationary series;

Term spread: the difference between long-term (10 years) government bond yield and the 90 days Treasury bill rate; 
$D A X$ : the real stock returns for Germany, computed as the first difference of the real DAX (Deutscher Aktien-Index) - a blue chip stock market index consisting of the 30 major German companies trading on the Frankfurt Stock Exchange;

$C A C$ : the real stock returns for France, computed as the first difference of the real CAC 40 (the benchmark French stock market index);

S\&P 500: the real stock returns for the United States, computed as the first difference of the real S\&P 500, which is the free-float capitalisation-weighted index of the prices of 500 large-cap common stocks;

FTSE 100: the real stock returns for the UK, computed as the first difference of the real FTSE 100 all-share index, which is a capitalisation-weighted index of around 100 companies traded on the London Stock Exchange;

NIKKEI: the real stock returns for Japan, computed as the first difference of the real Nikkei 225 stock index for the Tokyo Stock Exchange;

Hang-Seng: the real stock returns for Hong Kong, computed as the first difference of the real Hang Seng Index, which is a free float-adjusted market capitalisation-weighted stock market index.

Note, real stock price for each country was computed by deflating the respective nominal stock price index with the CPI for that country. Further, barring the Treasury bill rate, for which we use its first difference, all the other variables were found to be stationary based on standard unit roots tests, which are available upon request from the authors.

[INSERT TABLE 1 HERE]

\subsection{Analysing the individual predictive ability of the financial variables}

We used monthly data from 1990:01 to 2010:04 for the stock return and the financial variables. All the financial variables used (price-dividend ratio, price-earnings ratio, Treasury bill rate, term spread and the payout ratio) appear widely in the financial economics literature. The domestic stock prices are further affected by movements in the stock prices of the major trading partners and should exhibit a positive relationship. We include only countries with data available from 1989:10 or earlier, and these include Germany, France, USA, UK, Japan and Hong-Kong. These countries account over 60 per cent of the South Africa's trading partners. These stock returns also represent the major stock exchanges in the United States (S\&P 500), Europe (FTSE 100, DAX and CAC 40) and Asia (NIKKEI 225 and Hang Seng Index). The increase in price-dividend ratio, payout ratio and the term spread should be positively related to the stock return, while the price-earnings ratio and the Treasury bill rate are likely to be negatively related to the stock return. In Table 1 we report the descriptive statistic (the mean and the standard deviation) for the stock return and each of the financial variables included.

Table 2 reports the in-sample and the out-of-sample predictive ability of the financial variables for horizons $1,3,6,9,12,15,18$, and 24 . For the in-sample forecast we used the period 1990:01 to 1996:12 (120 time series data points), while for the out-of-sample forecast was from 1997:01 to 2010:04. The table further reports the $t$-statistics for the insample tests together with the Theil's U, the MSE-F and the ECN-NEW statistics for the out-of-sample tests. The p-values for the in-sample and the out-of-sample results reported in Table 2 are generated using the bootstrap procedure described earlier.

[INSERT TABLE 2 HERE]

Table 2 shows some interesting results, firstly only the stock returns for our major trading partners have in-sample predictive power at some horizons, where the $\mathrm{p}$-values 
are less than 10 per cent confidence level. The FTSE 100 and the NIKKEI are the only stock returns that have predictive power for all the horizons (up to 24 months), while the S\&P 500, the Hang Seng index and the CAC 40 can only predict stock returns for up to 18 months. Table 2 does not only show that all the stock returns have out-of-sample predictive power, but it also show that the treasury bill rate (two-month-ahead horizon to 15-month-ahead horizon, and 24-month ahead horizon) and the term spread (onemonth-ahead horizon) are the other financial variables that have out-of-sample predictive power. Similar to the in-sample test, only the FTSE 100 and the NIKKEI have longhorizon out-of-sample predictive power.

Overall, the results confirm proposals from McCracken (2004) as well as Clark and McCracken (2001) since the financial variables that have in-sample predictive power also have out-of-sample predictive power. Further, our results show that some financial variables only have out-of-sample predictive power. This might be as a result of the financial variables and international stock returns included in our analysis. Including a large number of financial variables in an attempt to predict stock price return renders the predictability tests susceptible to data mining, despite some of these variables exhibiting significant in-sample and out-of-sample predictive ability. Inoue and Kilian (2002) further show that both in-sample and out-of-sample forecasts are susceptible to data mining. Rapach and Wohar (2006) propose a bootstrap procedure in a data mining environment to control for data mining. The critical values of the bootstrap procedure under the data mining environment are reported in Table 3. Basically, we test for stock return predictability using $\beta=0$ for the null hypothesis for all financial variables in Table 2 and test it against the alternative hypothesis that $\beta>0$ for at least one of the financial variables using the maximal in-sample $t$-statistic and the maximal out-of-sample MSE-F and ENC-NEW statistics. The critical values for the maximal $t$-statistic and the maximal statistics of the MSE-F and ENC-NEW are reported in Table 3. We use the critical values in Table 3 to check whether the significance of the best statistic in Table 2 is mainly due to data mining.

[INSERT TABLE 3 HERE]

From Table 2, the maximal in-sample $t$-statistic of 6.932 at a one-month-ahead horizon corresponds to the FTSE 100. Using the critical values adjusted for data mining environment in Table 3, we see that the $t$-statistic remains significant at one percent. The out-of-sample maximal MSE-F statistic of 34.331 corresponding to the FTSE 100 at onemonth-ahead horizon remains significant at one per cent level when using the critical values reported in Table 3. For the ENC-NEW statistic, the maximal 26.976 corresponding to the FTSE 100 at a one-month-ahead horizon is also significant at one per cent level, when using critical values adjusted for data mining. Since all the in-sample and the out-of-sample test statistics remain significant when using critical values adjusted for data mining, the predictive ability of the FTSE 100 does not appear to attribute to data mining. At a three-month-ahead horizon, the maximal $t$-statistic corresponding to the FTSE 100 is 4.176. Using the critical values reported in Table 4, the maximal $t$ statistic is significant at one-per cent level. Further, the MSE-F statistic for the out-ofsample forecast is significant at ten per cent level when accounting for data mining. On the other hand, the ENC-NEW statistic becomes insignificant when using the data mining critical values at a three-month-ahead horizon. The results in Table 2 are somewhat robust for the 3-month-ahead horizon when we account for data mining. For the 6-month-ahead horizon to the 18-month-ahead horizon, only the in-sample maximal $t$-statistics (all corresponding to the FTSE 100) remain significant in a data mining environment, while there was no significant out-of-sample maximal statistics (neither the MSE-F statistic nor the ENC-NEW statistics) when accounting for data mining. For the 
24-month-ahead horizon, all the maximal test statistics are insignificant in a data mining environment. The results in Table 2, therefore, show that only the in-sample tests have robust predictive ability at longer horizons. The out-of-sample tests, however, show no evidence of predictability for stock returns at any horizon longer than 3 months ahead.

\subsection{General to specific model selection and out-of-sample forecasting ability}

\section{[INSERT TABLE 4 HERE]}

The results obtained by using the general-to-specific model specification are reported in Table 3. We combine the in-sample general to specific model selection with tests of sample forecasting ability. The in-sample period ends in 1962:02 and the out-of-sample period begins in 1997:01 for all the variables. Despite these variables' inability to predict stock price returns both in-sample and out-of-sample the valuation ratios are almost always included among the explanatory variables in the model selected over the in-sample period. The model also includes some stock return for on of our major trading partners. There are, however, only 3 of the other countries stock returns are included in different horizon (S\&P 500 index, FTSE 100, and the DAX). The model further shows that the explanatory variables increases, with the horizon, since at a one-month ahead there only are three explanatory variables while at 24 month-ahead horizon, the explanatory increases to five. Since the $U$ is greater than 0.9 for all horizons (horizon, 9, 12 and 24. $\mathrm{U}$ is greater than 1) the forecasting gains are typically small according to relative RMSE criterion. This basically means that the predictable component in South African stock returns is fairly small. The forecast encompassing tests indicate that the selected model contains information that is useful for forecasting beyond that contained into benchmark model.

\section{Conclusion}

In this paper, we examine the predictive ability of 5 financial variables and 6 global stock returns on stock return. We look at the two valuation ratios, term spread, Treasury bill rate, payout ratio, and stock returns of our major trading partners and use these variables for both the in-sample and the out-of-sample forecasts. The in-sample period starts from 1990:01 to 1996:12 and out-of-sample period is from 1997:01 to 2010:04. To account for data mining, we employ a data-mining-robust bootstrap procedure used by Rapach and Wohar (2006). Using this procedure we obtain critical values that account for data mining. Further, we combine the in-sample general-to-specific model selection with tests of out-of-sample forecasting ability.

Our results show that adding more financial variables does not improve the predictive ability of the valuation ratios. Further, only the stock returns for our major trading partners have in-sample predictive ability at any horizon. For the out-of-sample forecast, the stock returns of our trading partners together with the Treasury bill rate and the term-spread have some predictive ability at some horizon. Using critical values that account for data mining, we find that only the in-sample test statistics for all the horizons remain significant, while, for the out-of-sample forecasts, the MSE-F and the ENCNEW test statistics become insignificant from 6-month-ahead horizon. The results we obtain from the general-to-specific model show that the valuation ratios play a crucial role in explaining movements in stock returns, despite their inability to predict stock return when using in-sample and out-of-sample test statistics. The results from the model further show that the S\&P 500, FTSE 100 and the DAX are the main stock returns (from our trading partners) that explain movements in South Africa's stock returns. 
Although some of the financial variables are able to predict stock return at longer horizon, further research needs to be conducted which should be aimed at adding more macroeconomic variables in predicting stock returns. It would be interesting to see whether adding macroeconomic variables improves the predictive ability of stock returns (Rapach et al, 2005).

\section{References}

Ang, A. \& Bekaert, G. 2001. Stock return predictability: Is it there? National Burean of Economic Research, Working Paper No. 8207.

Apergis, N. \& Miller, S.M. 2004. Consumption Asymmetry and the Stock Market: Further Evidence. University of Connecticut, Department of Economics, Working Paper No 2004-19.

Apergis, N. \& Miller, S.M. 2005a. Consumption asymmetry and the stock market: New evidence through a threshold adjustment model. University of Connecticut, Department of Economics, Working Paper No 2005-08.

Apergis, N. \& Miller, S.M. 2005b. Resurrecting the Wealth Effect on Consumption: Further Analysis and Extension. University of Connecticut, Department of Economics, Working Paper No 2005-57.

Apergis, N. \& Miller, S.M. 2006. Consumption asymmetry and the stock market: Empirical evidence. Economics Letters, 93(3): 337-342.

Campbell, J.Y. \& Shiller, R. 1998. Valuation ratios and the long-run stock market outlook. Journal of Portfolio Management, Winter: 11-26.

Campbell, J.Y. 1987. Stock returns and the term structure. Joumal of Financial Economics, 18: 373-399.

Clark, T.E. 2004. Can out-of-sample forecast comparisons help prevent overfitting? Journal of Forecasting, 23: 115- 139.

Clark, T.E., \& McCracken, M.W. 2001. Tests of equal forecast accuracy and encompassing for nested models. Journal of Econometrics, 105: 85-110.

Das, S., Gupta, R. \& Kanda, P. Forthcoming. Bubbles in South African House Prices and their Impact on Consumption. Forthcoming in the Journal of Real Estate Literature.

Diebold, F.X. \& Mariano, S.R, 1995. Comparing predictive accuracy. Journal of Economics and Business Statistics 13: 253-263.

Gupta, R. \& Modise, M.P. 2010. Valuation Ratios and Stock Price Predictability in South Africa: Is it there? University of Pretoria, Department of Economics, Working Paper No.2010-16

Harvey, D.I., Leybourne, S.J. \& Newbold, P. 1998. Tests for forecast encompassing. Journal of Business and Economic Statistics, 16: 254-259.

Inoue, A. \& Kilian, L. 2002. In-sample or out-of-sample tests of predictability: Which one should we use? European Central Bank, Working paper No. 195

Kilian, L. 1999. Exchange rates and monetary fundamentals: What do we learn from long-horizon regressions? Journal of applied Econometrics, 14: 491- 510.

Kirby, C. 1997. Measuring the predictable variation in stock and bond returns. Review of Financial Studies, 10: 579-630.

Kothari, S.P. \& Shanken, J. 1997. Book-to-market, dividend yield, and expected market returns: A time series analysis. Journal of Financial Economics 44: 169-203.

Lamont, O. 1998. Earnings and expected returns. Journal of Finance 53: 1563-1587.

Lettau, M. \& Ludvigson, S.C. 2001. Consumption, Aggregate Wealth, and Expected Stock Returns. Journal of Finance, 56(3): 815-849. 
Lettau, M. \& Ludvigson, S.C. 2004. Understanding Trend and Cycle in Asset Values: Reevaluating the Wealth Effect on Consumption. American Economic Review, 94(1): 276-299.

Lettau, M., Ludvigson, S.C. \& Steindel, C. 2002. Monetary Policy Transmission Through the Consumption-Wealth Channel. FRBNY Economic Policy Review, May: 117133.

McCracken, M.W. 2004. Asymptotics for out-of-sample tests of causality. University of Missouri-Columbia, Manuscript.

Nelson, C.R. \& Kim, M.J. 1993. Predictable stock returns: the role of small sample bias. Journal of Finance 48: 641-661.

Newey, W. \& West, K.J. 1987. A simple, positive semi-definite, heteroskedasticity and autocorrelation consistent covariance matrix. Econometrica, 55: 703-708.

Pavlidis, I.E., Peel, D. \& Spiru, A. 2009. Bubbles in House Price and their Impact on Consumption: Evidence for the US. Lancaster University Management School Working Paper No. 2009/025.

Rapach, D. \& Strauss, J.K. 2006. The long-run relationship between consumption and housing wealth in the eighth district states. Federal Reserve Bank of St. Louis Regional Economic Development, 2(2): 140-147.

Rapach, D. \& Strauss, J.K. 2007. Habit Formation, Heterogeneity, and Housing Wealth Affects Across U.S. States. Missouri Economics Conference.

Rapach, D. \& Wohar, M.E. 2005. Valuation ratios and long-horizon stock price predictability. Journal of Applied Econometrics, 20: 327-344.

Rapach, D. \& Wohar, M.E. 2006. In-Sample vs. Out-of-Sample Tests of Stock Return Predictability in the Context of Data Mining. Journal of Empirical Finance, 13(2): 231-247.

Rapach, D., Strauss, J.K. \& Zhou, G. 2010. International Stock Return Predictability: What is the Role of the United States? St. Louis University Department of Economics Mimeo.

Rapach, D., Wohar, M.E \& Rangvid, J. 2005. Macro Variables and International Stock Return Predictability. International Journal of Forecasting, 21(1): 137-166. University of California at Los Angeles.

Stock, J.H. \& Watson, M.W. 2003. Forecasting Output and Inflation: The Role of Asset Prices. Journal of Economic Literature, 41: 788-829.

West, K.D. 1996. Asymptotic inference about predictive ability. Econometrica 64: 10671084. 
Table 1: Descriptive statistics, monthly data (1990:01-2010:04)

\begin{tabular}{llc}
\hline Variable & Mean & Standard deviation \\
\hline Allshare index & 0.099 & 2.188 \\
Price/Dividend ratio & 1.560 & 0.106 \\
Price/Earnings ratio & 1.149 & 0.096 \\
Payout ratio & 1.587 & 0.043 \\
Treasury Bills & -0.047 & 0.506 \\
Term spread & 0.804 & 1.947 \\
DAX & 0.147 & 2.829 \\
CAC & 0.051 & 2.496 \\
S\&P 500 & 0.118 & 1.907 \\
FTSE 100 & 0.036 & 1.864 \\
NIKKIE & -0.238 & 2.850 \\
Hang Seng & 0.246 & 3.342 \\
\hline Note: Germany = DAX (Deutscher Aktien-Index); France = CAC 40; \\
USA = S\&P 500; UK = FTSE 100 Index; Japan = Nikkei 225 \\
Hong Kong = Hang Seng Index
\end{tabular}


Table 2: In-sample and out-of-sample predictability test results, 1997:01-2010:04 out-of-sample period

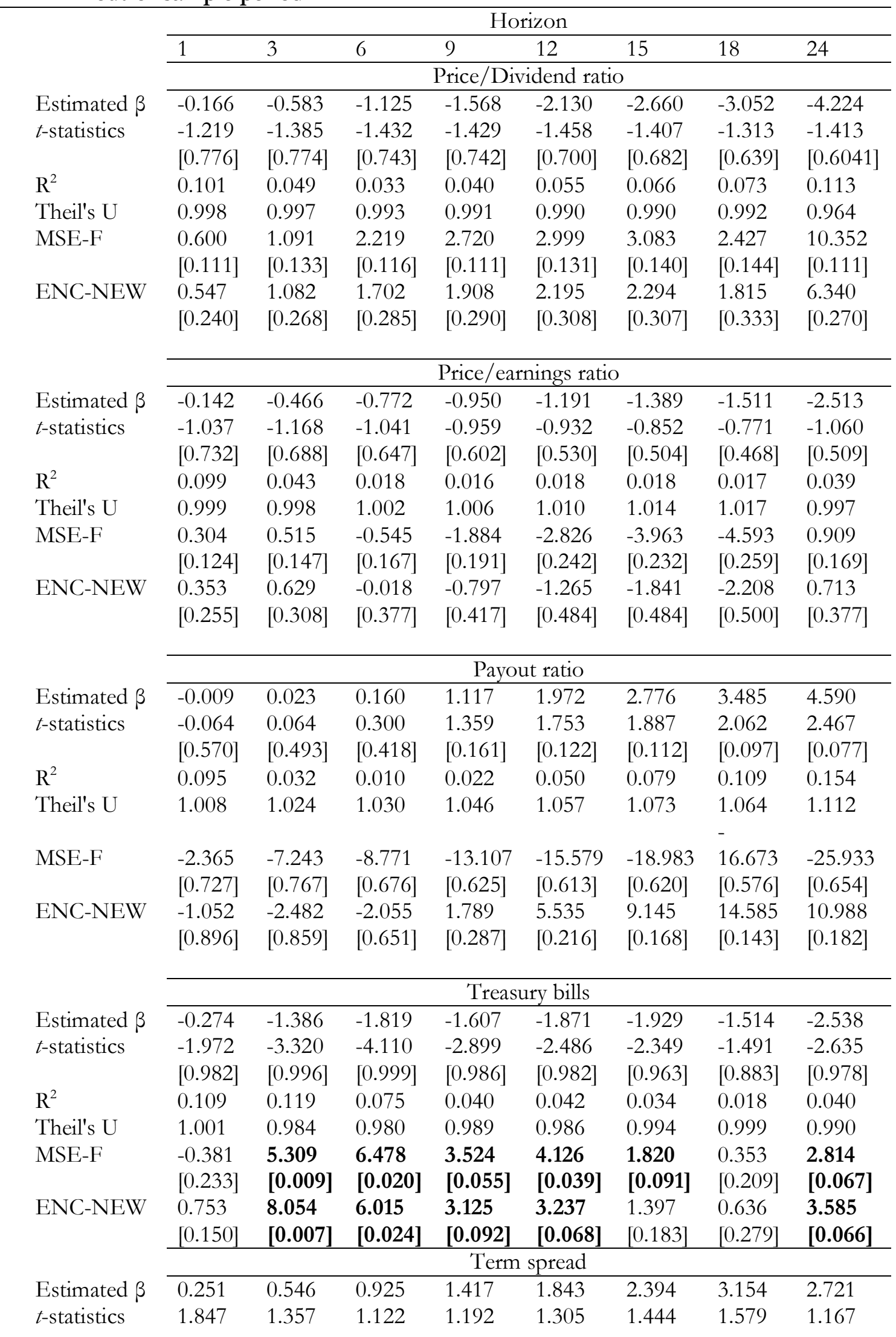




\begin{tabular}{|c|c|c|c|c|c|c|c|c|}
\hline & {$[0.108]$} & {$[0.122]$} & {$[0.174]$} & {$[0.175]$} & {$[0.165]$} & {$[0.160]$} & [0.144] & {$[0.231]$} \\
\hline $\mathrm{R}^{2}$ & 0.035 & 0.047 & 0.024 & 0.033 & 0.043 & 0.057 & 0.083 & 0.049 \\
\hline Theil's U & 0.997 & 1.001 & 1.010 & 1.017 & 1.018 & 1.016 & 1.007 & 1.025 \\
\hline \multirow{2}{*}{ MSE-F } & 0.854 & -0.191 & -3.092 & -5.103 & -5.158 & -4.475 & -1.978 & -6.588 \\
\hline & {$[0.067]$} & {$[0.148]$} & {$[0.259]$} & {$[0.320]$} & {$[0.334]$} & {$[0.339]$} & {$[0.254]$} & {$[0.387]$} \\
\hline \multirow[t]{3}{*}{ ENC-NEW } & 0.906 & 0.525 & -0.463 & -0.477 & 0.136 & 1.105 & 3.062 & -0.169 \\
\hline & {$[0.138]$} & {$[0.273]$} & {$[0.382]$} & {$[0.412]$} & {$[0.365]$} & {$[0.354]$} & {$[0.304]$} & [0.425] \\
\hline & \multicolumn{8}{|c|}{ DAX } \\
\hline Estimated $\beta$ & 0.669 & 0.548 & 0.735 & 0.790 & 0.778 & 0.728 & 0.390 & 0.453 \\
\hline \multirow[t]{2}{*}{$t$-statistics } & 4.887 & 1.705 & 1.872 & 1.295 & 1.466 & 1.266 & 0.632 & 0.590 \\
\hline & {$[0.000]$} & {$[0.056]$} & [0.039] & [0.119] & [0.099] & {$[0.135]$} & {$[0.304]$} & [0.338] \\
\hline $\mathrm{R}^{2}$ & 0.177 & 0.045 & 0.016 & 0.011 & 0.009 & 0.005 & 0.001 & 0.001 \\
\hline Theil's U & 0.959 & 1.003 & 1.004 & 1.008 & 1.002 & 1.005 & 1.005 & 1.005 \\
\hline \multirow[t]{2}{*}{ MSE-F } & 13.859 & -0.887 & -1.365 & -2.344 & -0.650 & -1.416 & -1.301 & -1.389 \\
\hline & {$[0.000]$} & {$[0.412]$} & {$[0.640]$} & {$[0.790]$} & {$[0.436]$} & {$[0.674]$} & {$[0.660]$} & [0.714] \\
\hline \multirow[t]{3}{*}{ ENC-NEW } & 13.454 & 0.572 & -0.125 & -0.786 & -0.131 & -0.521 & -0.506 & -0.558 \\
\hline & {$[0.000]$} & {$[0.188]$} & {$[0.444]$} & {$[0.830]$} & {$[0.479]$} & {$[0.733]$} & {$[0.748]$} & [0.810] \\
\hline & \multicolumn{8}{|c|}{ CAC } \\
\hline Estimated $\beta$ & 0.730 & 0.724 & 0.788 & 0.949 & 0.998 & 1.279 & 1.048 & 0.984 \\
\hline \multirow[t]{2}{*}{$t$-statistics } & 5.413 & 2.397 & 1.899 & 1.500 & 1.646 & 1.924 & 1.714 & 1.236 \\
\hline & {$[0.000]$} & {$[0.014]$} & {$[0.029]$} & {$[0.101]$} & {$[0.082]$} & {$[0.045]$} & {$[0.066]$} & [0.165] \\
\hline $\mathrm{R}^{2}$ & 0.194 & 0.055 & 0.017 & 0.015 & 0.013 & 0.015 & 0.008 & 0.006 \\
\hline Theil's U & 0.949 & 0.994 & 1.000 & 1.002 & 0.998 & 0.998 & 0.999 & 1.002 \\
\hline \multirow[t]{2}{*}{ MSE-F } & 17.394 & 2.007 & -0.144 & -0.739 & 0.590 & 0.495 & 0.184 & -0.433 \\
\hline & {$[0.000]$} & {$[0.038]$} & {$[0.206]$} & {$[0.406]$} & {$[0.140]$} & [0.141] & [0.188] & [0.418] \\
\hline \multirow[t]{3}{*}{ ENC-NEW } & 14.636 & 2.406 & 0.295 & -0.142 & 0.438 & 0.516 & 0.158 & -0.130 \\
\hline & {$[0.000]$} & {$[0.045]$} & {$[0.253]$} & {$[0.465]$} & {$[0.248]$} & [0.219] & {$[0.310]$} & [0.529] \\
\hline & \multicolumn{8}{|c|}{ S\&P 500} \\
\hline Estimated $\beta$ & 0.876 & 0.868 & 1.184 & 1.378 & 1.362 & 1.077 & 1.067 & 1.079 \\
\hline$t$-statistics & 6.870 & 3.500 & 3.129 & 2.623 & 2.518 & 1.600 & 1.963 & 1.440 \\
\hline & {$[0.000]$} & {$[0.000]$} & {$[0.000]$} & {$[0.011]$} & {$[0.021]$} & [0.089] & [0.049] & {$[0.123]$} \\
\hline $\mathrm{R}^{2}$ & 0.244 & 0.067 & 0.034 & 0.030 & 0.023 & 0.011 & 0.009 & 0.007 \\
\hline Theil's U & 0.903 & 0.986 & 0.992 & 0.992 & 0.993 & 1.001 & 0.999 & 1.000 \\
\hline \multirow[t]{2}{*}{ MSE-F } & 36.137 & 4.443 & 2.592 & 2.480 & 1.945 & -0.327 & 0.226 & -0.091 \\
\hline & {$[0.000]$} & {$[0.010]$} & {$[0.019]$} & {$[0.028]$} & [0.047] & {$[0.331]$} & {$[0.190]$} & [0.290] \\
\hline \multirow[t]{3}{*}{ ENC-NEW } & 32.185 & 5.653 & 2.731 & 2.427 & 2.063 & 0.172 & 0.351 & 0.154 \\
\hline & {$[0.000]$} & {$[0.004]$} & {$[0.034]$} & {$[0.040]$} & {$[0.068]$} & {$[0.314]$} & {$[0.252]$} & {$[0.362]$} \\
\hline & \multicolumn{8}{|c|}{ FTSE 100} \\
\hline Estimated $\beta$ & 0.900 & 1.106 & 1.562 & 1.811 & 1.710 & 1.868 & 1.622 & 1.726 \\
\hline$t$-statistics & 6.932 & 4.176 & 4.843 & 3.736 & 3.498 & 3.677 & 3.628 & 3.250 \\
\hline & {$[0.000]$} & {$[0.000]$} & {$[0.000]$} & {$[0.000]$} & {$[0.000]$} & {$[0.000]$} & {$[0.002]$} & [0.011] \\
\hline $\mathrm{R}^{2}$ & 0.246 & 0.086 & 0.054 & 0.048 & 0.033 & 0.031 & 0.020 & 0.017 \\
\hline Theil's U & 0.907 & 0.976 & 0.979 & 0.988 & 0.991 & 0.991 & 0.993 & 0.994 \\
\hline \multirow[t]{2}{*}{ MSE-F } & 34.331 & 7.710 & 6.605 & 3.743 & 2.707 & 2.676 & 1.897 & 1.684 \\
\hline & {$[0.000]$} & {$[0.000]$} & {$[0.001]$} & {$[0.014]$} & {$[0.030]$} & {$[0.022]$} & [0.049] & [0.071] \\
\hline \multirow[t]{3}{*}{ ENC-NEW } & 26.976 & 7.860 & 5.743 & 3.849 & 2.545 & 2.414 & 1.490 & 1.277 \\
\hline & {$[0.000]$} & {$[0.000]$} & {$[0.001]$} & {$[0.011]$} & {$[0.038]$} & {$[0.035]$} & [0.084] & {$[0.100]$} \\
\hline & \multicolumn{8}{|c|}{ NIKKEI } \\
\hline Estimated $\beta$ & 0.521 & 0.581 & 1.142 & 1.453 & 1.431 & 1.525 & 1.541 & 1.862 \\
\hline \multirow[t]{2}{*}{$t$-statistics } & 3.705 & 2.058 & 2.862 & 3.395 & 3.165 & 3.186 & 2.793 & 2.597 \\
\hline & {$[0.000]$} & {$[0.031]$} & {$[0.006]$} & [0.001] & [0.007] & {$[0.005]$} & {$[0.013]$} & [0.026] \\
\hline $\mathrm{R}^{2}$ & 0.144 & 0.047 & 0.030 & 0.031 & 0.023 & 0.020 & 0.018 & 0.020 \\
\hline
\end{tabular}




\begin{tabular}{|c|c|c|c|c|c|c|c|c|}
\hline Theil's U & 0.974 & 0.997 & 0.990 & 0.988 & 0.989 & 0.991 & 0.991 & 0.991 \\
\hline \multirow[t]{2}{*}{ MSE-F } & 8.600 & 0.875 & 3.060 & 3.654 & 3.179 & 2.662 & 2.539 & 2.448 \\
\hline & {$[0.000]$} & {$[0.082]$} & [0.021] & [0.011] & {$[0.018]$} & {$[0.030]$} & [0.029] & {$[0.036]$} \\
\hline \multirow[t]{3}{*}{ ENC-NEW } & 5.724 & 1.073 & 2.344 & 2.583 & 2.130 & 1.744 & 1.527 & 1.437 \\
\hline & {$[0.001]$} & {$[0.117]$} & [0.048] & {$[0.024]$} & {$[0.060]$} & {$[0.057]$} & {$[0.084]$} & [0.096] \\
\hline & \multicolumn{8}{|c|}{ Hang Seng } \\
\hline Estimated $\beta$ & 0.743 & 0.894 & 1.061 & 1.496 & 1.449 & 1.076 & 0.930 & 0.811 \\
\hline \multirow[t]{2}{*}{$t$-statistics } & 5.519 & 2.940 & 1.880 & 2.711 & 3.358 & 1.783 & 1.752 & 1.248 \\
\hline & {$[0.000]$} & {$[0.001]$} & [0.051] & {$[0.017]$} & {$[0.008]$} & {$[0.070]$} & {$[0.070]$} & [0.175] \\
\hline $\mathrm{R}^{2}$ & 0.197 & 0.067 & 0.028 & 0.034 & 0.025 & 0.011 & 0.007 & 0.004 \\
\hline Theil's U & 0.937 & 0.986 & 0.995 & 0.986 & 0.989 & 0.998 & 0.997 & 0.999 \\
\hline \multirow[t]{2}{*}{ MSE-F } & 21.965 & 4.593 & 1.630 & 4.392 & 3.210 & 0.459 & 0.955 & 0.357 \\
\hline & {$[0.000]$} & {$[0.006]$} & {$[0.061]$} & [0.009] & {$[0.027]$} & {$[0.184]$} & [0.105] & [0.194] \\
\hline \multirow[t]{2}{*}{ ENC-NEW } & 16.449 & 4.825 & 1.408 & 3.296 & 2.755 & 0.757 & 0.789 & 0.371 \\
\hline & {$[0.000]$} & {$[0.005]$} & [0.109] & {$[0.021]$} & [0.046] & {$[0.181]$} & [0.163] & {$[0.260]$} \\
\hline
\end{tabular}

Note: Estimated $\beta$ and $t$-statistic are the OLS estimate of $\beta$ in equation (1) and its corresponding $t$-statistic; $\mathrm{R}^{2}$ is the goodness-of-fit in equation (1);

$\mathrm{U}$ is the ratio of the RMSE for the out-of-sample forecasts for the unrestricted model to the RMSE for the out-of-sample forecasts for the restricted model;

MSE-F and ENC-NEW are the out-of-sample statistics; p-value are given in brackets; bold entries indicate significance at the 10 per cent level. 
Table 3: Data-mining bootstrap critical values

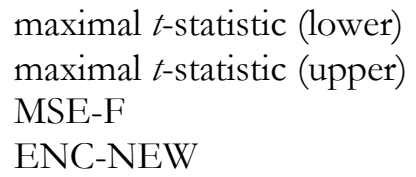

\begin{tabular}{ccc}
\multicolumn{3}{c}{ 1-month Horizon } \\
\hline 10 per cent & 5 per cent & 1 per cent \\
\hline-2.650 & -2.928 & -3.592 \\
2.542 & 2.757 & 3.309 \\
3.499 & 4.555 & 7.486 \\
4.125 & 5.306 & 7.069
\end{tabular}

\begin{tabular}{ccc}
\hline & 5.306 & 7.069 \\
\hline 10 per cent & 3-month Horizon & \\
\hline-3.069 & 5 per cent & 1 per cent \\
2.877 & -3.499 & -4.239 \\
6.572 & 3.156 & 3.827 \\
8.625 & 9.177 & 15.498 \\
& 11.179 & 19.578
\end{tabular}

\begin{tabular}{ccc}
\hline \multicolumn{3}{c}{ 6-month Horizon } \\
\hline 10 per cent & 5 per cent & 1 per cent \\
\hline-3.266 & -3.674 & -4.720 \\
3.082 & 3.576 & 4.313 \\
11.941 & 17.549 & 34.268 \\
16.688 & 21.051 & 35.584
\end{tabular}

\begin{tabular}{ccc}
\hline \multicolumn{3}{c}{ 9-month Horizon } \\
\hline 10 per cent & 5 per cent & 1 per cent \\
\hline-3.737 & -4.146 & -5.277 \\
3.269 & 3.711 & 4.722 \\
17.198 & 27.234 & 46.764 \\
22.319 & 31.999 & 55.045
\end{tabular}

\begin{tabular}{ccc}
\hline & 12-month Horizon \\
\hline 10 per cent & 5 per cent & 1 per cent \\
\hline-4.033 & -4.517 & -6.904 \\
3.521 & 3.961 & 5.310 \\
24.820 & 37.899 & 68.642 \\
30.276 & 42.608 & 74.314 \\
\hline
\end{tabular}

\begin{tabular}{ccc}
\hline & 15-month Horizon \\
\hline 10 per cent & 5 per cent & 1 per cent \\
\hline-4.417 & -5.029 & -6.942 \\
3.453 & 3.956 & 5.416 \\
29.242 & 40.788 & 84.874 \\
36.032 & 50.759 & 79.613 \\
\hline
\end{tabular}

\begin{tabular}{ccc}
\hline & 18-month Horizon \\
\hline 10 per cent & 5 per cent & 1 per cent \\
\hline-4.518 & -5.198 & -9.819 \\
3.584 & 4.097 & 5.874 \\
30.216 & 46.587 & 94.588 \\
35.993 & 50.115 & 89.815 \\
\hline
\end{tabular}

\begin{tabular}{ccc}
\hline & $24-$ month Horizon \\
\hline 10 per cent & 5 per cent & 1 per cent \\
\hline-5.430 & -6.141 & -8.115 \\
4.103 & 4.893 & 6.889 \\
39.463 & 57.394 & 108.905 \\
46.778 & 62.285 & 110.865
\end{tabular}

Notes: Critical values were computed using the data-mining bootstrap procedure described in section (2.3). The critical values correspond to the maximum values of the statistics reported in Table 2. 
Table 4: General-to-specific model selection results

\begin{tabular}{|c|c|c|c|c|c|c|c|c|}
\hline & \multicolumn{8}{|c|}{ Horizon } \\
\hline & 1 & 3 & 6 & 9 & 12 & 15 & 18 & 24 \\
\hline $\begin{array}{l}\text { Variables } \\
\text { included }\end{array}$ & France & $\begin{array}{l}\mathrm{P} / \mathrm{D} \\
\text { ratio, } \\
\mathrm{P} / \mathrm{E} \\
\text { ratio and } \\
\mathrm{S} \& \mathrm{P} 500\end{array}$ & $\begin{array}{l}\mathrm{P} / \mathrm{E} \\
\text { ratio, } \\
\text { term } \\
\text { spread } \\
\text { and } \\
\text { FTSE } \\
100\end{array}$ & $\begin{array}{l}\text { Payout } \\
\text { ratio and } \\
\text { FTSE } \\
100\end{array}$ & $\begin{array}{l}\mathrm{P} / \mathrm{D} \\
\text { ratio, } \\
\text { term } \\
\text { spread } \\
\text { and } \\
\text { FTSE } \\
100\end{array}$ & $\begin{array}{l}\mathrm{P} / \mathrm{D} \text { ratio, } \\
\mathrm{P} / \mathrm{E} \text { ratio, } \\
\text { payout } \\
\text { ratio, term } \\
\text { spread and } \\
\text { FTSE } 100\end{array}$ & $\begin{array}{l}\mathrm{P} / \mathrm{D} \text { ratio, } \\
\mathrm{P} / \mathrm{E} \text { ratio, } \\
\text { payout } \\
\text { ratio, } \\
\text { treasury } \\
\text { bills, term } \\
\text { spread and } \\
\text { DAX }\end{array}$ & $\begin{array}{l}\mathrm{P} / \mathrm{D} \text { ratio, } \\
\mathrm{P} / \mathrm{E} \text { ratio, } \\
\text { treasury } \\
\text { bills, term } \\
\text { spread } \\
\text { and } \mathrm{S} \& \mathrm{P} \\
500\end{array}$ \\
\hline $\bar{U}$ & 0.949 & 1.015 & 0.975 & 1.034 & 0.994 & 1.015 & 0.984 & 1.026 \\
\hline MSE-F & $\begin{array}{l}17.394 \\
{[0.000]}\end{array}$ & $\begin{array}{l}-4.589 \\
{[0.130]}\end{array}$ & $\begin{array}{l}8.161 \\
{[0.023]}\end{array}$ & $\begin{array}{l}-9.648 \\
{[0.129]}\end{array}$ & $\begin{array}{l}1.806 \\
{[0.053]}\end{array}$ & $\begin{array}{l}-4.249 \\
{[0.099]}\end{array}$ & $\begin{array}{l}4.661 \\
{[0.072]}\end{array}$ & $\begin{array}{l}-6.784 \\
{[0.147]}\end{array}$ \\
\hline $\begin{array}{l}\text { ENC- } \\
\text { NEW }\end{array}$ & $\begin{array}{l}14.636 \\
{[0.004]}\end{array}$ & $\begin{array}{l}3.529 \\
{[0.226]}\end{array}$ & $\begin{array}{l}10.169 \\
{[0.156]}\end{array}$ & $\begin{array}{l}5.029 \\
{[0.294]}\end{array}$ & $\begin{array}{l}12.647 \\
{[0.186]}\end{array}$ & $\begin{array}{l}20.958 \\
{[0.136]}\end{array}$ & $\begin{array}{l}32.856 \\
{[0.098]}\end{array}$ & $\begin{array}{l}20.783 \\
{[0.170]}\end{array}$ \\
\hline
\end{tabular}

Note: $\mathrm{U}$ is the ratio of the RMSE for the out-of-sample forecasts for the selected model to the RMSE for the outof-sample forecasts for the restricted model; MSE-F and ENC-New are the out-of-sample statistics; p-values are given in brackets; bold entries indicate significance at 10 per cent level. 